\title{
THE IMPORTANCE OF WILLOW THICKETS FOR PTARMIGAN AND HARES IN SHRUB TUNDRA: THE MORE THE BETTER?
}

\author{
Dorothée Ehrich ${ }^{1}$, John-ANdré Henden ${ }^{1}$, Rolf ANKer IMS ${ }^{1}$, LILYIA O. DoroninA ${ }^{2}$, Siw Turid \\ Killengren ${ }^{1}$, Nicolas LeComte ${ }^{1}$, IVAn G. Pokrovsky ${ }^{1,3}$, Gunnhild SKOgStad ${ }^{1}$, AleXander A. \\ Sokolov ${ }^{4}$, Vasily A. Sokolov ${ }^{5}$, And Nigel Gilles Yoccoz ${ }^{1}$
}

${ }^{1}$ Department of Arctic and Marine Biology, University of Troms $\phi, 9037$ Tromso, Norway. E-mail: dorothee.ehrich@uit.no

${ }^{2}$ Biological Faculty of Lomonosov Moscow State University, 1 Leninskie Gory, Moscow 119991, Russia

${ }^{3}$ A.N. Severtsov Institute of Ecology and Evolution, Russian Academy of Sciences, 33 Leninskij prospekt, Moscow 119071, Russia

${ }^{4}$ Ecological Research Station of the Institute of Plant and Animal Ecology, Ural Division Russian Academy of Sciences, 21 Zelyonaya Gorka, Labytnangi, Yamalo-Nenetski district 629400, Russia

${ }^{5}$ Institute of Plant and Animal Ecology, Ural Division Russian Academy of Sciences, 202, 8 Marta Street, Ekaterinburg 620144, Russia

\begin{abstract}
In patchy habitats, the relationship between animal abundance and cover of a preferred habitat may change with the availability of that habitat, resulting in a functional response in habitat use. Here, we investigate the relationship of two specialized herbivores, Willow Ptarmigan (Lagopus lagopus) and Mountain Hare (Lepus timidus), to willows (Salix spp.) in three regions of the shrub tundra zone - northern Norway, northern European Russia and western Siberia. Shrub tundra is a naturally patchy habitat where willow thickets represent a major structural element and are important for herbivores both as food and shelter. Habitat use was quantified using feces counts in a hierarchical spatial design and related to several measures of willow thicket configuration. We document a functional response in the use of willow thickets by ptarmigan, but not by hares. For hares, whose range extends into forested regions, occurrence increased overall with willow cover. The occurrence of Willow Ptarmigan showed a strong positive relationship to willow cover and a negative relationship to thicket fragmentation in the region with lowest willow cover at landscape scale, where willow growth may be limited by Reindeer (Rangifer tarandus) browsing. In regions with higher cover, in contrast, such relationships were not observed. Differences in predator communities among the regions may contribute to the observed pattern, enhancing the need for cover where willow thickets are scarce. Such region-specific relationships reflecting regional characteristics of the ecosystem highlight the importance of large-scale investigations to understand the relationships of habitat availability and use, which is a critical issue
\end{abstract}


considering that habitat availability changes quickly with climate change and human impact. Reproduced with permission of the authors from Oecologia, Online First ${ }^{T M}, 21$ July 2011. http://dx.doi.org/10.1007/s00442-011-2059-0

Ehrich, D., J.-A. Henden, R. A. Ims, L. O. Doronina, S. T. Killengren, N. Lecomte, I. G. Pokrovsky, G. Skogstad, A. A. Sokolov, V. A. Sokolov, And N. G. Yoccoz. 2011. The importance of willow thickets for ptarmigan and hares in shrub tundra: The more the better? Reproduced, pages 125-140 in R. T. Watson, T. J. Cade, M. Fuller, G. Hunt, and E. Potapov (Eds.). Gyrfalcons and Ptarmigan in a Changing World, Volume II. The Peregrine Fund, Boise, Idaho, USA. http://dx.doi.org/10.4080/gpcw.2011.0214

Keywords: Habitat use, habitat fragmentation, occupancy, availability, large scale.

THE AVAILABILITY OF SUITABLE HABITATS determines the distribution of animals at different scales (Johnson 1980, Mayor et al. 2009, Orians and Wittenberger 1991). As animals select their habitat to meet all their needs for successful reproduction and survival, the optimal habitat is often composed of a mixture of patches of several habitat types (Orians and Wittenberger 1991). For instance, different habitats may be optimal for foraging, shelter and/or breeding, resulting in trade-off situations (e.g., Mysterud et al. 1999). Habitat and landscape selection can in such cases vary in space in relation to changes in availability of important landscape elements (Fortin et al. 2008). A positive relationship between animal abundance and cover of a particular habitat may, for instance, be restricted to a certain range of cover values and flatten out or even decrease at higher values, meaning that the preference for a given type of habitat may change with its availability. Such a relationship has been defined as a functional response in habitat use (Mysterud and Ims 1998). Understanding how animal abundance and habitat area are related is an important question in ecology, in particular as the availability of habitats changes quickly with climate change and human impact.

Shrubs provide important ecological functions in many open habitats (Ripple and Beschta 2005). Willow thickets are a characteristic component of shrub tundra vegetation (Cher- nov and Matveeva 1997, Walker et al. 2005) and represent a good example of a patchy habitat. Willows (Salix spp.) usually grow along rivers or on slopes and are often the tallest plants in the tundra landscape (Pajunen 2009, Pajunen et al. 2010). The thickets represent a major structural element and are highly productive habitats compared to the surrounding low-statured tundra vegetation. They provide food, shelter, and/or breeding sites for numerous species of insects, birds, and mammals (den Herder et al. 2004, 2008, Ims et al. 2007, Henden et al. 2010). Under global change, the growth of shrubs is increasing in the tundra, and shrubs are expanding northwards (Sturm et al. 2001, Tape et al. 2006, Wookey et al. 2009). At the same time, in some parts of the Arctic, willow growth is reduced and thickets are fragmented due to intense browsing by abundant ungulates, mostly Reindeer (Rangifer tarandus) (Den Herder et al. 2004, 2008, Forbes et al. 2009, Kitti et al. 2009). These two opposing processes lead to varying areal extent of willows in climatically comparable regions (Pajunen et al. 2010).

Two important herbivores, the Willow Ptarmigan (Lagopus lagopus, hereafter ptarmigan) and the Mountain Hare (Lepus timidus, hereafter hare) can be considered as willow specialists in Arctic environments. Ptarmigan depend strongly on willow shrubs, which constitute their most important food resource (West and Meng 1966, Andreev 1988, Elson et 
al. 2007, Hakkarainen et al. 2007) and provide cover in an otherwise barren landscape, in particular in winter (Estaf'ev and Mineev 1984, Tape et al. 2010). Recently, Henden et al. (2011) documented increased occurrence of ptarmigan in patches with higher cover of willow thickets in northeastern Norway. At the same time, they reported a negative effect of increased fragmentation of willow thickets. Hares are a widespread species in the tundra and boreal forest of Eurasia (Kolosov et al. 1965, Newey et al. 2007). In the erect shrub tundra in the northern part of their range, willow thickets and the adjacent productive meadows are the optimal habitat for hares (Labutin 1988, Shtro 2006). Willow shrubs are main food plants in winter and spring (Pavlinin 1997, Newey et al. 2007), whereas they constitute a sheltered habitat for reproduction in summer (Labutin 1988).

The relationship of these two specialized herbivores to willow thickets, whose extent varies strongly between regions in the shrub tundra, represents a good model system to investigate whether habitat use changes in relation to availability. The aim of our study is to determine whether regional abundance of ptarmigan and hare and the intensity of use (i.e. selection) of willow habitats, changes with the availability of this habitat, which is liable to change in response to impacts of climate and abundant ungulates. Building on the study of Henden et al. (2011) on ptarmigan in Finnmark, northernmost Norway, we applied the same method-counts of fecal pellets on permanent plots in replicate riparian landscapesin two comparable tundra regions in the Russian Arctic. The three regions form a gradient in the amount of willow thickets. Specifically, we asked whether there was a general positive relationship between the amount of willows at a large scale (landscape scale) and the occurrence of ptarmigan and hares, and whether these two herbivores also consistently preferred willow thicket habitats in regions with more willows. In a second step, we investigated whether the positive effect of willow cover and the negative effect of fragmentation at a smaller scale on the presence of ptarmigan reported by Henden et al. (2011) were also observed in regions with more willow thickets. Finally, we asked whether hare reacted in the same way to differences in the configuration of willow thickets.

\section{MATERIALS AND METHODS}

Study Areas-The study was carried out in three regions within the southern arctic shrub tundra zone (Walker et al. 2005): Finnmark in northeastern Norway $\left(70.4^{\circ} \mathrm{N}, 29^{\circ} \mathrm{E}\right)$, the Nenetsky Ridge in Nenetsky Autonomous Okrug, Russia $\left(68.3^{\circ} \mathrm{N}, 53.3^{\circ} \mathrm{E}\right)$ and southern Yamal, Russia $\left(68.2^{\circ} \mathrm{N}, 69.1^{\circ} \mathrm{E}\right)$ (Figure 1).

The study area in Finnmark has been described in detail in Henden et al. (2010) and Killengreen et al. (2007). The landscape is mountainous with elevations up to $500 \mathrm{~m}$ a.s.1. and sparse vegetation above $400 \mathrm{~m}$. The mountain slopes are dominated by heaths mainly composed of dwarf shrubs, whereas the valleys are more productive and willow thickets surrounded by meadows grow on the riparian plains forming the valley bottom. The thicket communities in this region resemble the forbrich types described by Pajunen et al. (2010), but differ from them in exact species composition. The coast near tundra on Varanger Peninsula in the eastern part of the area is classified as erect dwarf shrub tundra (Walker et al. 2005), but there is large intra-zonal variation due to topography and a variety of substrate types (Virtanen et al. 1999). The western part of the area at Ifjordfjellet lies in sub-arctic alpine tundra with similar main vegetation characteristics (Killengreen et al. 2007).

Nenetsky Ridge is situated in the buffer zone of the State Nature Reserve Nenetsky and consists of a tundra plateau with gentle slopes reaching up to $140 \mathrm{~m}$ a.s.1. Our study area is situated on the eastern slope of the Ridge. It includes three rivers with relatively deep (up to $70 \mathrm{~m}$ ) and narrow (ca. $300 \mathrm{~m}$ ) valleys. Two 


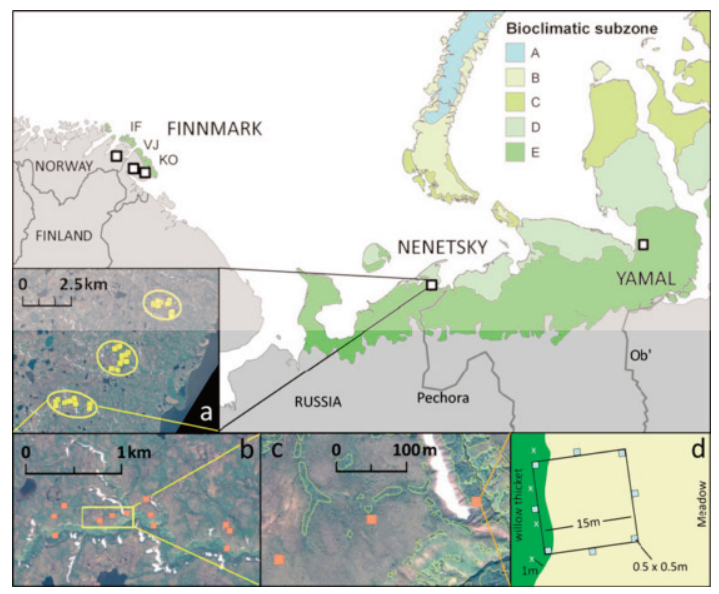

Figure 1. The study regions relative to the Bioclimatic subzones defined by Walker et al. (2005). In Finnmark, IF refers to Ifjordfjellet, VJ to Vestre Jakobselv, and KO to Komag. The insets show an overview of the study design.

a) Three units in three small valleys in Nenetsky.

b) Triplets of plots representing each of three habitat types were chosen.

c) The contour of willow thickets was drawn on satellite images or aerial photographs in order to estimate their surface.

d) Each plot comprised eight small quadrates where feces were counted. Willow (W) plots were in meadows at the edge of willow thickets.

of the valleys do not have a floodplain at their bottom, and the river flows directly between the two slopes. The river valleys are dominated by willow thickets (mainly $S$. glauca and $S$. phylicifolia) interspersed with lush meadow vegetation characterized by high species diversity and plants of high productivity (Skogstad 2009). The thicket communities in the valleys belong to the forb-rich types of Pajunen et al. (2010), resembling the Salix-Trollius-Geranium type and the Salix-Comarum palustreFilipendula ulmaria type. Some willow thickets also grow on the plateau, interspersed with tundra vegetation.
The study area in Yamal is situated in the southern part of the Peninsula, close to the confluence of the Payutayakha and Erkutayakha rivers. It is characterized by flat tundra interspersed with hills (up to $40 \mathrm{~m}$ high) with sometimes steep slopes, and sandy cliffs along rivers. The tundra is subdivided by a dense network of rivers and lakes, and many low-lying areas are flooded in spring. The area lies at the border between erect dwarf-shrub tundra and low-shrub tundra (Walker et al. 2005). Willow thickets are sometimes interspersed with Alnus and form communities which are close to the S. glauca-Carex aquatilis type (Pajunen et al. 2010). Some of the thicket communities can also be classified as Salix lanata-myosotis nemorosa type.

\section{Study Design}

Our study followed a hierarchical design with several nested levels. At the largest scale, we compared the three study regions (Figure 1). The region Finnmark consisted of three subregions which will here be treated collectively, because ptarmigan response to willow thicket areal extent and fragmentation was highly consistent among them (Henden et al. 2011). In each study region or sub-region sampling plots were arranged in units (two to four; see Figure 1a), usually valleys. Within units, study plots were selected along willow thickets growing along the river as well as in the adjacent tundra (Figure 1b-d). The selection of units and plots within units was made to cover the existing variation in willow thicket areal extent and fragmentation within the unit. Units were separated by at least $2 \mathrm{~km}$. Willow thicket plots (W) and tundra plots within each unit were, as far as possible, arranged as pairs or triplets (Figure 1b, c). Plots in tundra vegetation were thus chosen in proximity of $\mathrm{W}$ plots; however, at least $30 \mathrm{~m}$ from the edge of meadows or thickets. The nearest neighbor distance between plots in the same habitat was on average $513 \mathrm{~m}(\min 129, \max 2,359 \mathrm{~m})$ and the 
distance between plots belonging to the same pair/triplet was on average $151 \mathrm{~m}$ (min $36 \mathrm{~m}$, $\max 420 \mathrm{~m}$ ).

The vegetation on $\mathrm{W}$ plots, a productive meadow dominated by herbaceous dicotyledons and grasses, placed along a willow thicket (Figure 1d; Henden et al. 2010), was chosen to be as homogenous as possible within and among the different study regions and to represent the most productive parts of the ecosystem. We chose willow thickets that were at least $0.5 \mathrm{~m}$ high and were growing on riparian plains or valley/hill slopes. Thickets growing on rocks or in mires, or which were flooded were excluded (Henden et al. 2010). Tundra plots, in contrast, differed among the regions. In Finnmark, tundra plots were chosen to represent the dwarf shrub heath that dominates the tundra landscapes in northern Fennoscandia (Virtanen et al. 1999, Moen 1998). These heaths are mainly composed by evergreen (Empetrum nigrum hermaphroditum) and deciduous dwarf shrubs (Vaccinium spp., Betula nana; Ravolainen et al. 2010). In Nenetsky, tundra plots were chosen in two of the most common vegetation types: Shrub tundra plots (S) were characterized by B. nana and ericoid shrubs (Vaccinium spp., Rhododendron tomentosum), interspersed with sedges (Carex spp.) and Rubus chamaemorus, and hummock tundra plots $(\mathrm{H})$ were dominated by cottongrass tussocks (Eriophorum spp.) interspersed with dwarf shrubs and $R$. chamaemorus (Skogstad 2009). In Yamal, tundra plots were also chosen in two vegetation types which dominated in the landscape: dry tundra plots (D) were characterized by ericoid dwarf shrubs, mainly $R$. tomentosum but also Vaccinium spp., B. nana and Eriophorum spp., and moist tundra plots $(\mathrm{M})$ were dominated by thick layers of Sphagnum moss together with Carex spp. and Eriophorum spp. tussocks, interspersed with $R$. chamaemorus and $B$. nana. Most tundra plots were situated on slopes or in the upland tundra, except the moist tundra plots in Yamal, which were placed in the lower flat tundra. Because of the configu- ration of the landscape, most plots were not grouped as triplets in Yamal.

Feces Counts and Willow Thicket Variables.Ptarmigan and hares produce conspicuous fecal pellets, which can be used as an index of abundance and habitat use (Krebs et al. 2001, Evans et al. 2007, Ims et al. 2007). In Varanger, the Willow Ptarmigan is sympatric with the Rock Ptarmigan (Lagopus muta). However, the Rock Ptarmigan mainly uses other habitat types, at higher altitudes than considered in this study. Fecal pellets were counted in eight permanently marked small quadrates of $0.5 \times 0.5 \mathrm{~m}$ arranged around a 15 x 15 m study plot (Figure 1d). Counts were performed twice per year, shortly after snow melt in spring (spring) and in the second part of August/beginning of September (fall), from 2005 to 2009 in Finnmark (a few plots were excluded from the counts in 2009 because of a change in the monitoring protocol) and from 2007 to 2009 in Russia. After counting, feces were removed from the plots. As feces had not been removed previous to spring 2007 in Nenetsky and Yamal, the counts from spring 2007 may represent cumulative use over more than one winter. Occurrence in spring 2007 may thus be overestimated. However, here we are primarily focusing on the relative abundance of fecal pellets in relation to willow thicket configuration and the possible accumulation is unlikely to bias the results on relative habitat use.

The areal extent and degree of fragmentation of willow thickets were derived from aerial photographs (Finnmark) as described in Henden et al. (2010), or from Quickbird satellite images with a resolution of $0.6 \mathrm{~m}$ (Russian regions; Digital-Globe ${ }^{\mathrm{TM}}$ 2001). For the Russian regions, the outlines of the thickets were digitized in ArcGIS (ESRI ${ }^{\mathrm{TM}}$ ). Thickets were considered distinct when they were separated by an open area of at least $2 \mathrm{~m}$, as such an opening could be identified with reasonable confidence on the pictures. We quantified the areal extent of willow thicket as percent wil- 
low cover in squares of $2 \times 2 \mathrm{~km}$ (C-land) and $200 \times 200 \mathrm{~m}$ (C-loc) using the software FRAGSTATS (McGarigal et al. 2002). Squares were centered on each study plot (except for C-land in Finnmark where the measurement was centered on each unit). Thicket fragmentation was quantified as patch density (number of patches per 4 ha; PD) and edge density (meters of edge per 4 ha; ED) measured in squares of $200 \times 200 \mathrm{~m}$ centered on each plot. An increase in both of these measures reflects increased fragmentation or shredding (cf. Feinsinger 1994) of willow thickets. Choice of spatial scale is important in habitat selection studies (e.g., Mayor et al. 2009, Henden et al. 2010). However, in the absence of specific data on the scale of area use of individual hares and ptarmigan in the study regions, the focal scales were chosen arbitrarily based on the spatial constraints of the study design; the local scale was the largest possible avoiding overlapping willow configuration measurements, whereas the landscape scale corresponded roughly with the size of the study units.

The vertical structure of the willow thickets was described by willow height (W-height) and density (W-density). These were measured at four points situated at $1 \mathrm{~m}$ inside the edge of the willow thicket along the side of the plot. Density was determined as the number of times a willow bush (leaf or branch) touched a vertical pole placed at the measuring point (point intercepts) and height was the highest willow branch within $25 \mathrm{~cm}$ of the pole. The mean of the four measurements was taken as the value for each plot.

Statistical Analysis.-The data were analyzed at two hierarchical levels for each species. First, in order to compare the effect of C-land in the three regions, the analysis was carried out at the level of the unit. Estimates of C-land thus originated from spatially non-overlapping squares for each replicate, minimizing spatial autocorrelation (Eigenbrod et al. 2010). The number of small quadrats with presence of feces was summed over all study plots belonging to the same habitat type within each unit, season, and year and used as binary response variable (number of small quadrats with presence versus number of small quadrats with absence per habitat/unit/season/year, referred to as occurrence in the following). Generalized linear mixed effects model (GLMM) with a logit link and a binomial distribution were used for the analysis. Fixed effects were C-land (for the Russian sites an average value was used for each unit), habitat, region, season, and year (as factors). We used only the years with observations in all three regions (2007-2009) for the statistical analysis. In order to be applicable in all regions, habitat was coded as W versus tundra plots, thus pooling the different tundra types (T, H, S, D, M). Unit identity was used as random effect to account for repeated measurements in the same plots. C-land was standardized by scaling it with mean $=0$ and standard deviation $=0.5$ to make effect estimates comparable with the two-level factor habitat (Gelman and Hill 2007). The preference of ptarmigan and hares for the different tundra types in the Russian regions was analyzed separately using Chi-square tests.

Second, we considered the effect of the configuration of willow thickets directly surrounding each $\mathrm{W}$ plot on habitat use by herbivores. Here, we summed the number of small quadrats where feces were present among the eight small quadrats arranged around each plot, and used it as a binary response variable in GLMM as above. C-loc quantified willow cover at this scale. We used PD as measure of thicket fragmentation. On the satellite picture from Yamal, it was not always easy to trace edges precisely, and we thus considered PD a more robust indicator of willow fragmentation than ED in this case. Some of the willow configuration variables were strongly correlated, such as Wheight and W-density in Yamal $(r=0.77$; Electronic Supplementary Material, ESM, Table S1). We nevertheless included them in the analysis, as Smith et al. (2009) showed that in studies of habitat fragmentation it is best to 
include all variables despite possible correlations. In addition to these four willow configuration variables, region, year, and season were included as fixed effects, and plot identity was used as random effect. For all analyses, the best model was selected among eight candidate models comprising an additive model as well as models with interactions of willow and habitat variables with region, year, or season. All willow variables were kept in all candidate models (Smith et al. 2009). In addition, an interaction of season with year was considered.

Statistical analyses were carried out in $\mathrm{R}$ version 2.9.2 (R Development Core Team 2010). GLMMs were fitted using the Laplace approximation as implemented in the lme4 package (Bates et al. 2008). Log-likelihood ratio tests were used to compare the candidate models and a model was considered superior to the next simpler model when $\mathrm{P}<0.05$. Selected models were checked for constant variance of the residuals, presence of outliers and approximate normality of the random effects. A few (1-8) outliers were detected in the four analyses. However, since removing them did not alter the results qualitatively and only modified estimates slightly, all data were retained in the analysis.

\section{RESUlTS}

Regional Patterns of Willow Thicket Configuration.-The extent and fragmentation, as well as the vertical structure of willow thickets, differed considerably between the regions (Table $1)$. The extent of willow cover at the large scale ( 2 × $2 \mathrm{~km}$; C-land) was lowest in Finnmark, much higher in Nenetsky, and intermediate in Yamal. At the local scale, considering willow cover in the vicinity of W plots $(200 \mathrm{x}$ $200 \mathrm{~m}$; C-loc), the contrasts were not as strong, and C-loc was on average lowest in Yamal. The vertical structure of the willow thickets also exhibited a contrasting pattern. Willow thickets were lower in Yamal than in the two other regions, whereas thicket density was highest in Nenetsky (Table 1). Altogether, the clearest contrasts in willow thicket configuration variables were between Nenetsky and the two other regions and variation among plots was smallest in Yamal (ESM Fig. S1).

Regional Patterns of Herbivore Abundance.There were considerable differences in occurrence of ptarmigan and hares between the regions (Figure 2). The occurrence of ptarmigan was highest in Nenetsky and lower but rather similar in Yamal and eastern Finnmark. The occurrence of hares was also highest in Nenetsky and somewhat lower in Yamal, whereas hares were almost absent from Finnmark (Figure 2). Therefore, this region was excluded from the statistical analysis of hare occurrence. There was a clear seasonal effect for both species, with fewer feces found in the fall (Figure 2). Such a difference may partly be due to the difference in the length of the seasons (about 2 months in summer compared to the rest of the year). As the fall observation was missing in 2007 and 2009 in Yamal, only spring was analyzed for this region.

Landscape Scale Habitat Use.-For ptarmigan occurrence at the large scale, the best model included an interaction between region and the two habitat variables, C-land and habitat, as well as between year and season. Willow cover at the scale of units had no significant effect on the overall occurrence of ptarmigan in the Russian regions. In Finnmark, in contrast, where willow cover was on average lowest (Table 1), occurrence increased with C-land (logit estimate $=6.29, \mathrm{SE}=2.06$; ESM Figure S2). Considering habitat, in Yamal, occurrence was nearly twice as low on tundra plots as on $\mathrm{W}$ plots (logit estimate for $\mathrm{T}$ plots with $\mathrm{W}$ plots as reference $=-0.56, \mathrm{SE}=0.26$, odds ratio $=$ 0.57). In Finnmark, the preference of ptarmigan for W plots was even stronger (logit estimate for $\mathrm{T}$ plots $=-1.83, \mathrm{SE}=0.30$, odds ratio $=0.16$ ), whereas in Nenetsky, where willow cover was on average highest, ptarmigan clearly preferred tundra plots (logit estimate for $\mathrm{T}$ plots $=0.96, \mathrm{SE}=0.17$, odds ratio $=$ 2.62). In addition, occurrence was significantly 

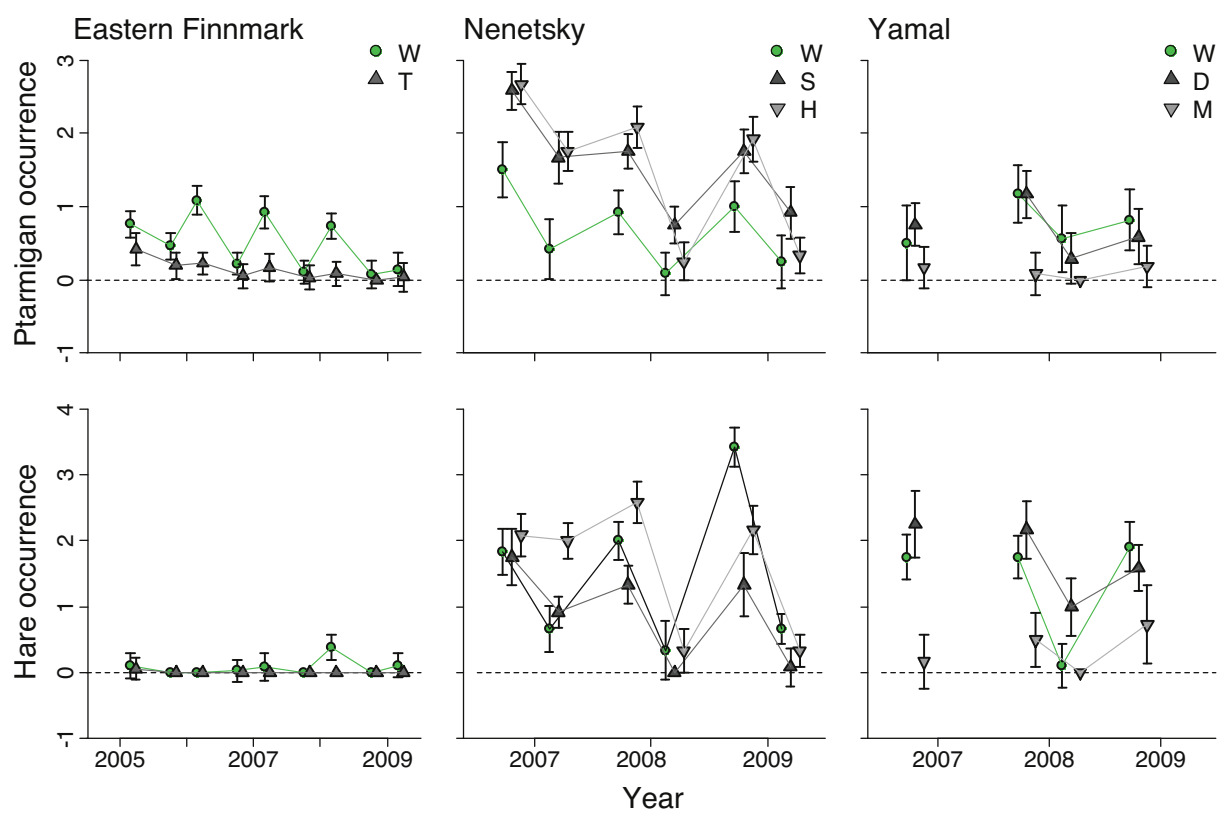

Figure 2. Occurrence of feces of Willow Ptarmigan (Lagopus lagopus) and Mountain Hare (Lepus timidus) in the three study regions is plotted for each habitat type. W meadow plots at the edge of willow thickets, $\mathrm{T}$ tundra plots in eastern Finnmark, S shrubby tundra, $\mathrm{H}$ hummock tundra, D dry tundra, and $\mathrm{M}$ moist tundra (see main text for a description of the habitat types). Occurrence refers to the number of small quadrates surrounding a plot where feces were recorded. For each year, spring and fall counts are shown.

Table 1. Willow thicket configuration variables presented as means and ranges (in brackets) for the three study regions: number of plots (n), percent willow cover estimated on plots of $2 \times 2 \mathrm{~km}$ (C-land), percent willow cover estimated on plots of $200 \times 200 \mathrm{~m}$ (C-loc), patch density (PD) and edge density (ED), both measured on plots of $200 \times 200 \mathrm{~m}$.

\begin{tabular}{llll}
\hline & Finnmark & Nenetksy & Yamal \\
$\mathrm{n}$ & 37 & 12 & 12 \\
C-land (\% area) & $1.8(0.6-3.5)$ & $23.6(17.9-30.5)$ & $11.1(1.2-22.7)$ \\
C-loc (\% area) & $19.8(1.4-54.3)$ & $35.0(13.1-52.6)$ & $12.3(1.5-31.9)$ \\
PD (nb patches/4 ha) & $18.5(1-87)$ & $29.5(10-69)$ & $8.5(3.0-16.1)$ \\
ED (m edge/4 ha) & $1,760(367-4,036)$ & $2,933(1,120-4,908)$ & $1,021(293-1,904)$ \\
W-height (m) & $1.61(0.78-2.70)$ & $1.70(1.05-2.38)$ & $0.82(0.53-1.24)$ \\
W-density (nb of hits) & $2.5(0.3-5.5)$ & $6.4(2.3-9.5)$ & $3.6(2.0-6.5)$ \\
\hline
\end{tabular}



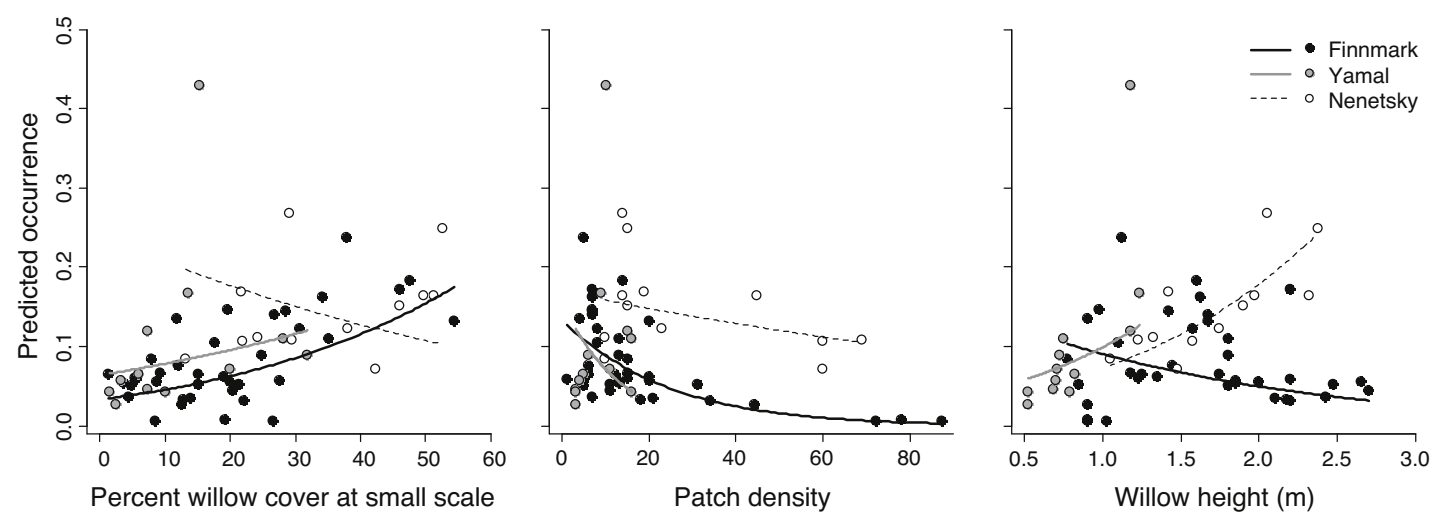

Figure 3. Local scale: ptarmigan occurrence in willow plots in the three study regions in spring 2008 as a function of willow cover and patch density in the 4 ha surrounding each plot and as a function of willow height in the plots. Points show values predicted from the selected model, and lines show relationships given average values for the other predictor variables.

lower in fall than in spring, an effect which was strongest in 2008 (see ESM Table S2 for complete model output). Chi-square tests showed that in Nenetsky overall ptarmigan occurrence did not differ between the two tundra types $\left(\chi^{2}=0.11, \mathrm{df}=2, \mathrm{P}=0.74\right)$, whereas in Yamal ptarmigan clearly avoided $\mathrm{M}$ plots $\left(\chi^{2}=17.86, \mathrm{df}=2, \mathrm{P}<0.001\right)$.

The best model for hare occurrence in the Russian regions at the large scale included interactions of the two habitat variables with year and the interaction between year and season. There was a general positive effect of willow cover on occurrence per unit (logit estimate $=1.66, \mathrm{SE}=0.31 ; \mathrm{ESM}$ Figure S2). There was no consistent difference between the two habitat types over the years, but more hare feces were found on W plots in 2009 in both regions (see ESM Table S3 for complete model output). As for ptarmigan, occurrence was lower in fall than in spring. The difference between the seasons was smaller in 2007 than in subsequent years (ESM Table S3). Considering tundra types, hares clearly avoided $\mathrm{M}$ plots in Yamal $\left(\chi^{2}=35.64, \mathrm{df}=2, \mathrm{P}<0.001\right)$, whereas in Nenetsky they avoided $\mathrm{S}$ plots $\left(\chi^{2}=13.41, \mathrm{df}\right.$ $=2, \mathrm{P}<0.001)$. These habitat preferences were consistent over seasons (Figure 2).
Local Scale Habitat Use.-Considering only willow plots and their direct surroundings (200 x $200 \mathrm{~m}$ ), the best model for ptarmigan occurrence included interactions of the willow configuration variables with region. For Finnmark, we observed a positive effect of C-loc and a negative effect of thicket fragmentation, a result consistent with Henden et al. (2011). In addition, there was a negative effect of Wheight, which was not significant in the previous analysis. The estimates of the effect of W-height were, however, not very different between the two analyses, which included a different set of years and explanatory variables (e.g., ED instead of PD). The variables used were strongly correlated, reflecting the same pattern of willow configuration, but the exact choice of variables to include can modify the estimates of the other effects (Smith et al. 2009). In Nenetsky, in contrast, there was no effect of any of the willow configuration variables on the occurrence of ptarmigan and the contrasts in slope with Finnmark as reference level were significant (Figure 3; ESM Table S4). In Yamal, the effects of willow configuration were not different from those observed in Finnmark. 
Figure 4. Hare occurrence in function of willow patch density in the 4 ha surrounding each plot at the edge of a willow thicket, and in function of willow height. Points show values predicted from the selected model, and lines show relationships given average values for the other predictor variables.
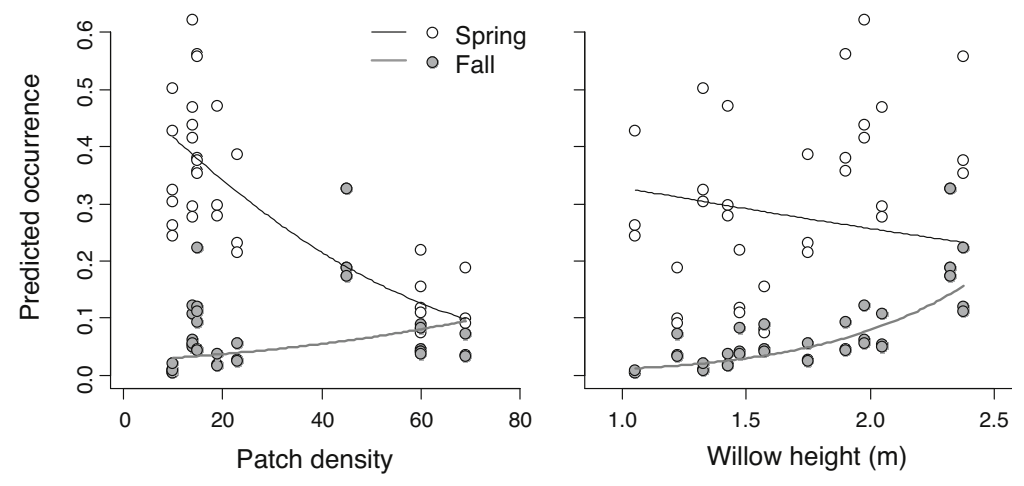

For hares, the best model at the local scale included interactions of the willow configuration variables with season. As fall counts were missing in Yamal, these interactions could be estimated only for Nenetsky. In Nenetsky, PD had a negative effect on hare occurrence in spring (logit estimate $=-1.37, \mathrm{SE}=0.37$ ), but not in fall (Figure 4). There was also a significant contrast in the effect of W-height, which was slightly negative in spring but positive in fall (Figure 4; ESM Table S5). Considering only spring counts from both regions produced consistent results and revealed a similar negative effect of PD, indicating that in winter hares prefer less fragmented willow thickets.

\section{Discussion}

For ptarmigan, we showed that the importance of willow thickets for the relative abundance and habitat use decreased with increasing extent of willow thickets in the region. This was the case both at the scale of units and at local scale of plots. Within each region, the effects were surprisingly consistent over years and seasons. In eastern Finnmark, where willow thickets occupy only a very small proportion of the landscape, are restricted to rather narrow riparian plains and may be additionally fragmented by intense Reindeer browsing (Henden et al. 2010), there was a significant positive relationship between willow cover at the large scale and the occurrence of ptarmigan. This result was in clear contrast to the
Russian regions, where willow cover was higher but did not relate to ptarmigan occurrence. At the same time, the preference of ptarmigan for $\mathrm{W}$ plots was highest in eastern Finnmark, whereas in Nenetsky, where willow cover was highest and thickets also occur on the plateau between the valleys, ptarmigan preferred tundra plots. In Yamal, willow cover was intermediate and ptarmigan preferred $\mathrm{W}$ plots, but not as strongly as in eastern Finnmark. At the local scale of $\mathrm{W}$ plots and their direct surroundings, our results show that the positive effect of willow cover and negative effect of fragmentation reported by Henden et al. (2011) for Finnmark was also observed in Yamal. In Nenetsky, in contrast, where W plots were not the preferred habitat, ptarmigan did not select plots with relatively higher willow cover and less fragmented thickets. This may be explained by the general abundance of willows in Nenetsky, but also by the fact that the range of C-loc and PD did not include equally low values in Nenetsky as in the other regions (Table 1).

Altogether, we thus documented a functional response in habitat use (Mysterud and Ims 1998) for ptarmigan with respect to willow thickets - an important resource both as food and as shelter. Ptarmigan show increasing preference for habitats situated at the edge of willow thickets when the amount of thickets on the regional level decreases. This is likely to be also true for the inner part of the thickets, but 
our observations allowed us only to compare the thicket edge to the open tundra. Furthermore, within regions with a low amount of willows (such as in eastern Finnmark), ptarmigan prefer local areas or landscape sections with large homogenous willow thickets. Indeed, the contrasting results between Finnmark and the two Russian sites indicate that willow thickets may be a limiting resource for ptarmigan in Finnmark, where ptarmigan occurrence, a proxy for abundance, decreases strongly with decreasing willow cover, and ptarmigan seldom use open tundra (cf. Henden et al. 2011). Whether the willows are most important in terms of forage or protective cover is unknown. However, cover may be particularly important in presence of specialized avian predators such as Gyrfalcon (Falco rusticolus) (Nystrom et al. 2005) and Golden Eagle (Aquila chrysaetos) (Johnsen et al. 2007, Nystrom et al. 2005, 2006). Both these raptors are quite common year round residents in Finnmark, while they do not breed in the two Russian regions. Furthermore, ptarmigan in Finnmark selected willow thickets equally strongly in summer and in winter, although willow twigs are most foraged in winter (Tape et al. 2010). The affinity for willow thickets in summer, when the diet shifts in part to other species such as Dryas spp., Bistorta vivipara or Ericaceae berries (Weeden 1969, Williams et al. 1980), underlines the importance of willow thickets as cover for ptarmigan in this region. The preference for willow habitats in Yamal in winter was not as strong as in Finnmark and was in fact due to avoidance of the flat and Sphagnum-dominated M plots. D plots and $\mathrm{W}$ plots were used equally in this region, as could be expected if ptarmigan experienced lower predation pressure and thus less need for cover. The preference for tundra habitats in Nenetsky was also consistent with a reduced need for cover, and may be additionally explained by topography and landscape characteristics. Willow thickets in the deep valleys in Nenetsky are likely to be covered by thick layers of snow in winter making them less accessible for foraging than thickets on the plateau. In summer, the lush and high meadow vegetation on W plots (Skogstad 2009) may be little suitable for ptarmigan.

In Finnmark, ptarmigan preferred lower willows, but this was not the case in Nenetsky. Yamal, where willow thickets were on average lowest, was not significantly different from Finnmark in this respect, although the parameter estimate was similar to that from Nenetsky (Figure 3), not indicating any preference for low willows. The different effect of willow height is likely to be due to different willow architecture. In Finnmark, W-height and W-density were not correlated, and some of the higher shrubs had few lower branches where ptarmigan could feed. In the Russian regions, willow shrubs were more dense and likely to offer equal feeding opportunities at different heights.

As overall level of occurrence of ptarmigan was highest in Nenetsky and lower in eastern Finnmark, an alternative explanation for the region-specific use of tundra habitat could be density-dependent habitat selection. Accordingly, the use of tundra habitats would increase when the regional abundance increases due to competition for optimal habitats (e.g., Fretwell 1972). However, habitat use did not differ between the seasons although the level and mode of competition between ptarmigan is expected to change with seasons as they are territorial in summer but gather in flocks in winter (Storch 2007). Thus, we consider this explanation unlikely.

For hares, region-specific habitat selection could only be analyzed in the two Russian regions where the contrast in willow cover was less. Nevertheless, our results showed that hare occurrence at the landscape scale was higher where willow cover was higher, and this effect was not different between the regions. Because their distribution extends far into forested habitats of the boreal and temperate zone (Kolosov et al. 1965), hares may be less dependent on the characteristic patchy structure of shrub tundra than ptarmigan. Hares did not exhibit any 
clear preference for a particular habitat. Their occurrence was higher on W plots in 2009, but not in the two other years. At the local scale, hares preferred less fragmented thickets in winter, but this was not the case in summer. In winter, larger thickets may provide more continuous foraging opportunities and better protection. In summer, in contrast, hares feed mostly in open habitats such as meadows (Labutin 1988, Pavlinin 1997), which are likely to be most accessible in a landscape with smaller willow patches.

In addition to differences in region-specific habitat selection, our data indicated differences in regional abundance of ptarmigan and hares. The overall occurrence of ptarmigan was highest in Nenetsky and lower in Yamal and eastern Finnmark, whereas the occurrence of hares was slightly higher in Nenetsky than in Yamal, and very low in Finnmark (Figure 2). Because sampling was stratified to include main habitat types in each region, overall occurrence reflects regional abundance. When discussing ptarmigan abundance, the multi-annual population dynamics of the species should be considered (Storch 2007). In Finnmark, ptarmigan numbers have consistently decreased over recent years, a decline which can neither be explained directly by willow thicket degradation nor by a predator-mediated effect of small rodent dynamics (Henden et al. 2011). In Yamal, the years of our study were years of low ptarmigan abundance (V.A. Sokolov, personal communication), whereas the dynamics in Nenetsky are unknown. Nevertheless, overall regional abundance of both species seemed positively correlated with the amount of willow thickets. Several nonexclusive hypotheses may explain the observed differences in regional abundance. Assuming that willow thicket growth in Finnmark is affected by intense Reindeer browsing (Den Herder et al. 2004, 2008, Kitti et al. 2009), a negative impact of Reindeer numbers on medium-sized herbivores could be hypothesized (Ims et al. 2007). This interpretation, involving a trophic bottom-up effect, should, however, be completed by considerations of the predator community, which also differs between the regions. In addition to the presence of avian predators during winter (see above), Red Foxes (Vulpes vulpes) - an important predator for both hare and ptarmigan - are more abundant in Finnmark than in the Russian regions, where Arctic Foxes (V. lagopus) dominate (Killengreen et al. 2007, Arctic Predators project, unpublished). Raven (Corvus corax) and Crow (C. cornix), two generalist predators which have been shown to have a negative impact on Rock Ptarmigans in Scotland (Watson and Moss 2004), are also considerably more abundant in Finnmark than in the Russian regions (Killengreen 2010, Arctic Predators project, unpublished). Total predation pressure is thus likely to be higher in Finnmark and may contribute to lower abundance. Our data do not, however, allow us to present more than suggestive correlations concerning regional abundance as many factors, such as multi-annual population dynamics (Storch 2007, Newey et al. 2007) or the influence of hunting, which is likely to be stronger in Norway than in Russia, were not considered.

\section{Conclusions}

Investigating the importance of willow thickets for two medium-sized herbivores in three different shrub tundra regions revealed clear differences in region-specific abundance and habitat selection. We document a functional response in the use of willow habitats by ptarmigan, but not for hares. Region-specific relationships reflecting the regional particularities of the landscape and ecosystem highlight the importance of large-scale investigations to understand the relationships of habitat availability and use. Under climate change, willow shrubs are likely to expand in the arctic tundra, a process which may be limited by browsing of large herbivores (Post and Pedersen 2008). Understanding how medium-sized herbivores may react to changes in willow cover and thicket configuration will add an important element to predictions of how the arctic tundra ecosystem may change in the near future. Wil- 
low thickets are, however, only one component of the ecosystem influencing abundance and habitat selection of ptarmigan and hare. A complete understanding of the changes in the position of these herbivores in the tundra ecosystem will require the integration of other factors, such as predation (Lima and Dill 1990).

\section{ACKNOWLEDGMENTS}

We are grateful to Eeva Soininen, Ingrid Jensvoll, Anna Rodnikova, Victor Sidorov, Olga Kulikova and many others for great contributions to the field work, and we thank two anonymous reviewers for their comments on a previous version of the paper. This study was financed by the Research Council of Norway through the projects "EcoFinn" and "IPY-Arctic Predators" (http://www.arctic-predators.uit.no).

\section{Literature Cited}

AndreEv, A. 1988. The 10 year cycle of the Willow Grouse of lower Kolyma. Oecologia 76:261-267.

Bates, D., M. Maechler, And B. DAi. 2008. lme4: linear mixed-effects models using S4 classes [Computer software]. http://cran. rproject.org/

Chernov Yu. I., And N. V. Matveyeva. 1997. Arctic ecosystems in Russia. Pages 361507 in F. E. Wielgolaski (Ed.). Ecosystems of the World, vol. 3: Polar and Alpine Tundra. Elsevier, Oxford, UK.

Den Herder, M., R. Virtanen, AND H. RoiniNEN. 2004. Effects of Reindeer browsing on tundra willow and its associated insect herbivores. Journal of Applied Ecology 41:870-879.

DEN Herder, M., R. VirTANen, AND H. RoinINEN. 2008. Reindeer herbivory reduces willow growth and grouse forage in a forest-tundra ecotone. Basic and Applied Ecology 9:324-331.

EIgENBrod, F., S. J. HeCNAR, AND L. FAHRIG. 2010. Sub-optimal design has major impacts on landscape-scale inference. Bio- logical Conservation. http://dx.doi.org/10. 1016/j.biocon.2010.09.007

Elson, L. T., F. E. Schwab, AND N. P. P. SIMON. 2007. Winter food habits of Lagopus lagopus (Willow Ptarmigan) as a mechanism to explain winter sexual segregation. Northeastern Naturalist 14:89-98.

Estaf'ev, A. A., and Yu. N. Mineev. 1984. Seasonal distribution of Willow Ptarmigan in tundra of European north-east of USSR. In Animals - Components of the Ecosystem of the European North and Ural. University of Syktyvkar, Russia (in Russian).

Evans, S. A., F. Mougeot, S. M. RedPATH, AND F. LECKIE. 2007. Alternative methods for estimating density in an upland game bird: The Red Grouse Lagopus lagopus scotieus. Wildlife Biology 13:130-139.

Feinsinger, P. 1994. Habitat "shredding." Pages 258-260 in G. K. Meffe and C. R. Carroll (Eds.). Principles of Conservation Biology. Sinauer Associates, Sunderland, Massachusetts, USA.

Forbes, B. C., F. Stammler, T. Kumpula, N. Meschtyb, A. Pajunen, and E. KaARleJARVI. 2009. High resilience in the YamalNenets social-ecological system, West Siberian Arctic, Russia. Proceedings of the National Academy of Science, USA 106:22041-22048.

Fortin, D., R. Courtois, P. Etcheverry, C. Dussault, AND A. Gingras. 2008. Winter selection of landscapes by woodland caribou: Behavioural response to geographical gradients in habitat attributes. Journal of Applied Ecology 45:1392-1400.

Fretwell, S. D. 1972. Populations in a Seasonal Environment. Princeton University Press, Princeton, New Jersey, USA.

Gelman, A., AND J. HiLl. 2007. Data Analysis Using Regression and Multilevel/Hierarchical Models. Cambridge University Press, New York, USA.

Hakkarainen, H., R. Virtanen, J. O. HonkaNEN, AND H. RoININEN. 2007. Willow bud and shoot foraging by ptarmigan in relation to snow level in NW Finnish Lapland. Polar Biology 30:619-624. 
Henden, J. -A., R. A. Ims, N. G. Yoccoz, R. Sørensen, And S. T. Killengreen. 2010. Population dynamics of tundra voles in relation to configuration of willow thickets in southern arctic tundra. Polar Biology http://dx.doi.org/10.1007/s00300010-0908-7

Henden, J.- A., R. A. Ims, N. G. Yoccoz, AND S. T. Killengreen. 2011. Declining Willow Ptarmigan populations: The role of habitat structure and community dynamics. Basic and Applied Ecology 12:413-422.

Ims, R. A., N. G. Yoccoz, K. A. BRÅthen, P. Fauchald, T. TVERAa, AND V. Hausner. 2007. Can Reindeer overabundance cause a trophic cascade? Ecosystems 10:607622.

Johnsen, T. V., G. H. Systad, K. O. Jacobsen, T. NygARD, AND J. O. Bustnes. 2007. The occurrence of Reindeer calves in the diet of nesting Golden Eagles in Finnmark, northern Norway. Ornis Fennica 84:112-118.

Johnson, D. H. 1980. The comparison of usage and availability measurements for evaluating resource preference. Ecology 61:65-71.

KiLlengreen, S. T. 2010. Sources of spatial variation in food web structure in low Arctic tundra. Ph.D. dissertation, University of Troms $\varnothing$, Troms $\varnothing$, Norway.

Killengreen, S. T., R. A. IMs, N. G. Yoccoz, K. A. BrÅthen, J. -A. Henden, And T. SCHOтт. 2007. Structural characteristics of a low Arctic tundra ecosystem and the retreat of the Arctic Fox. Biological Conservation 135:459-472.

Kitti, H., B. C. Forbes, and J. Oksanen. 2009. Long- and short-term effects of Reindeer grazing on tundra wetland vegetation. Polar Biology 32:253-261.

Kolosov, A. M., N. P. LaVRov, AND S. P. NAUMOV. 1965. Mountain Hare-Lepus timidus L. Pages 328-335 in Biology of Hunted Animals of the USSR. Vyshaya Shkola, Moskva, Russia (in Russian).

Krebs, C. J., R. Boonstra, V. Nams, M. O'Donoghue, K. E. Hodges, and S. Boutin. 2001. Estimating Snowshoe Hare population density from pellet plots: A further evaluation. Canadian Journal of Zoology 79:1-4.

LABUTIN, Y. V. 1988. Particularities of the spatial distribution and behaviour of Mountain Hares (Lepus timidus) in Yakutia as adaptations of the species to northern conditions. Russian Journal of Ecology 2:40-44 (in Russian).

LiMA, S. L., AND L. M. DiLl. 1990. Behavioral decisions made under the risk of predation-A review and prospectus. Canadian Journal of Zoology 68:619-640.

Mayor, S. J., D. C. Schneider, J. A. SchaeFER, AND S. P. MAHONEY. 2009. Habitat selection at multiple scales. Ecoscience 16:238-247.

McGarigal, K., S. A. Cushman, M. C. Neel, AND E. ENE. 2002. FRAGSTATS: Spatial Pattern Analysis Program for Categorical Maps. Computer software program produced by the authors at the University of Massachusetts, Amherst, Massachusetts, USA.

Moen, A. (1998) Nasjonalatlas for Norge: Vegetasjon. Statens kartverk, Hønefoss, Norway.

Mysterud, A., AND R. A. Ims. 1998. Functional responses in habitat use: Availability influences relative use in trade-off situations. Ecology 79:1435-1441.

Mysterud, A., P. K. Larsen, R. A. Ims, And E. Ostbye. 1999. Habitat selection by Roe Deer and sheep: Does habitat ranking reflect resource availability? Canadian Journal of Zoology 77:776-783.

Newey, S., T. Willebrand, D. T. Haydon, F. DAhl, N. J. AEbischer, A. A. SMith, AND S. J. Thirgood. 2007. Do Mountain Hare populations cycle? Oikos 116:1547-1557.

Nyström, J., J. Ekenstedt, A. ANGerbjörn, L. Thulin, P. Hellström, AND L. DAlen. 2006. Golden Eagles on the Swedish mountain tundra-Diet and breeding success in relation to prey fluctuations. Ornis Fennica 83:145-152.

NySTRÖM, J., J. EKENSTEDT, J. ENGSTRÖM, AND A. ANGERBJÖRn. 2005. Gyr falcons, ptarmi- 
gan and microtine rodents in northern Sweden. Ibis 147:587-597.

ORIANS, G. H., AND J. F. WitTENBERGER. 1991. Spatial and temporal scales in habitat selection. American Naturalist 137:29-49.

Pajunen, A. M. 2009. Environmental and biotic determinants of growth and height of arctic willow shrubs along a latitudinal gradient. Arctic, Antarctic, and Alpine Research 41:478-485

Pajunen, A. M., E. M. KaArlejårvi, B. C. Forbes, AND R. ViRTANEN. 2010. Compositional differentiation, vegetation-environment relationships and classification of willow-characterised vegetation in the western Eurasian Arctic. Journal of Vegetation Science 21:107-119.

Pavlinin, V. V. 1997. Particularities of the ecology of Mountain Hare (Lepus timidus) in Yamal. Pages 31-42 in Materialy po istorii i sovremennomu sostoyaniyu fauni severa Zapadnoy Sibiri (in Russian).

Post, E., And C. Pedersen. 2008. Opposing plant community responses to warming with and without herbivores. Proceeding of the National Academy of Science, USA 105:12353-12358.

R Development Core Team. 2010. R: A Language and Environment for Statistical Computing. R Foundation for Statistical Computing, Vienna, Austria.

Ravolainen, V. T., N. G. Yoccoz, K. A. BRÅTHEN, R. A. IMS, M. IVERSEN, AND V. T. GONZÁLEZ. 2010. Additive partitioning of diversity reveals no scale-dependent impacts of large ungulates on the structure of tundra plant communities. Ecosystems 13:157-170.

RipPle, W. J., AND R. L. Beschta. 2005. Refugia from browsing as reference sites for restoration planning. Western North American Naturalist 65:269-273.

ShTRO, V. G. 2006. Notes about the behaviour of Mountain Hares in the tundra of Yamal. Nauchniy Vestnik YNAO 1(38):173-174 (in Russian).

Skogstad, G. 2009. Does habitat fragmentation of willow thickets have spill-over effects on tundra vegetation? M.S. thesis, University of Troms $\varnothing$, Troms $\varnothing$, Norway. SMith, A. C., N. Koper, C. M. Francis, AND L. FAHRIG. 2009. Confronting collinearity: Comparing methods for disentangling the effects of habitat loss and fragmentation. Landscape Ecology 24:1271-1285.

Storch, I. 2007. Grouse: Status and Conservation Action Plan 2006-2010. IUCN, Gland, Switzerland and World Pheasant Association, Fordingbridge, UK.

Sturm, M., C. Racine, And K. TAPe. 2001. Climate change - Increasing shrub abundance in the Arctic. Nature 411:546-547.

TAPE, K. D., R. LORD, H. P. MARShall, AND R. W. RUESS. 2010. Snow-mediated ptarmigan browsing and shrub expansion in arctic Alaska. Ecoscience 17:186-193.

TAPe, K., M. Sturm, and C. Racine. 2006. The evidence for shrub expansion in Northern Alaska and the Pan-Arctic. Global Change Biology 12:686-702.

VIRTANEN, R., L. OKSANEN, AND V. Y. RAZZHIVIN. 1999. Topographical and regional patterns of tundra heath vegetation from northern Fennoscandia to the Taimyr Peninsula. Acta Botanica Fennica 167:2983.

Walker, D. A., M. K. Raynolds, F. J. A. Daniels, E. EINARSSON, A. ElvebakK, W. A. Gould, A. E. Katenin, S. S. Kholod, C. J. Markon, E. S. Melnikov, N. G. Moskalenko, S. S. Talbot, and B. A. YURTSEV. 2005. The circumpolar Arctic vegetation map. Journal of Vegetation Science 16:267-282.

WATSON, A., AND R. Moss. 2004. Impacts of ski-development on ptarmigan (Lagopus mutus) at Cairn Gorm, Scotland. Biological Conservation 116: 267-275.

WEEDEN, R. B. 1969. Foods of Rock and Willow Ptarmigan in central Alaska with comments on interspecific competition. Auk $86: 271-281$.

West, G. C., AND M. S. MeNG. 1966. Nutrition of Willow Ptarmigan in northern Alaska. Auk 83:603-615. 
Williams, J. B., D. Best, And C. Warford. 1980. Foraging ecology of ptarmigan at Meade River, Alaska. Wilson Bulletin 92:341-351.

WoOkey, P. A., R. Aerts, R. D. Bardgett, F. Baptist, K. A. BrÅthen, J. H. C. CoRnelissen, L. Gough, I. P. Hartley, D. W. Hopkins, S. LAVOREL, AND G. R. SHAVER. 2009. Ecosystem feedbacks and cascade processes: Understanding their role in the responses of Arctic and alpine ecosystems to environmental change. Global Change Biology 15: 1153-1172. 